\title{
"It Would Be Better If You Can Hang Out With Different People": An Examination of Cross-National Interaction in Postsecondary Classrooms
}

Christopher J. Johnstone

University of Minnesota

Diana Yefanova

University of Minnesota

Gayle Woodruff

University of Minnesota

Mary Lynn Montgomery

University of Minnesota

Barbara J. Kappler

University of Minnesota

\begin{abstract}
This study examines the motivations and experiences of international and domestic students on three U.S. campuses related to cross-national interactions within classroom settings. The study also examines the role of instructors in facilitating such interactions through individual and group interviews. Findings indicate that domestic students appreciate the global perspectives of international students related to course content. International students, in turn, appreciate the "real world" perspectives that domestic students provide about the US (but do not necessarily find value in their content-related comments). The implications of this study are that cross-national interactions have different meanings for different stakeholders (i.e., some perceive to benefit academically while others perceive to benefit culturally). The implications of this study relate to how instructors structure student interactions and what might be reasonable outcomes for students in international groups in postsecondary classrooms.
\end{abstract}




\section{Introduction}

Internationalization of higher education has become a nearly ubiquitous term in postsecondary institutions. Knight (2015) has set out guideposts for the process by periodically updating her definition of the process. Most recently, in 2015, Knight noted that "internationalization, at the national, sector, and institutional levels is defined as the process of integrating an international, intercultural, or global dimension into the purpose, functions, or delivery of postsecondary education" (p. 2). Knight's (2015) umbrella definition allows for systems and institutions to design their own pathway in the internationalization process. As noted by Childress (2009), this pathway is often in response to the impacts of globalization, which institutions cannot control. Jones, Coelen, Beelen, and de Wit (2016), however, also note that internationalization approaches and strategies are strongly rooted in local political agendas and resource availability.

In general, internationalization of higher education is a broad and encompassing concept that, at the local level, has many strategies aimed at the enterprises of administration, partnerships, research, and students. In this study we chose to focus on a subset of the internationalization strategy present in many universities - enrolment of international students. Such enrolment is part of a broader student mobility agenda, operationalized as the outward international flow of domestic students in study abroad and the inward flow of international students to study at U.S. campuses (American Council on Education, 2016). In this study we focus specifically on the classroom environment and interactions of international and domestic students in the postsecondary classroom.

\section{Study Context and Rationale}

Although this qualitative study did not posit specific hypotheses, our theoretical perspective draws upon decades of work related to strategies of facilitating positive outcomes of intercultural contacts in the learning environments. The study focus leads to the brief review of the concept of internationalization at home (IaH) that highlights spreading the benefits of higher education internationalization to a much wider segment of students than those who study abroad, especially domestic students with limited opportunities to travel abroad (Crowther et al., 2000). The initial emphasis in the IaH model was divided among three principal components: (a) diversity as a resource; (b) an internationalized curriculum; and (c) a culturally sensitive pedagogy. For the purpose of this study we focus on the first and the third components of this conceptual model.

Within the U.S. context, where our study was conducted, international students are identified as an important contributor to diversity on campuses (Zhao, Kuh, \& Carini, 2005). College classrooms may be the best place on campus to leverage the diversity of views and experiences that international students may bring (Shapiro, Farrelly, \& Tomaš, 2014) and where positive benefits of engaging with international diversity in the classroom may be realized for all students. 


\section{Outcomes of Cross-National Interactions}

Over the past several decades, scholars have identified cross-cultural learning environments as spaces of opportunity for cognitive development (Bruning, Schraw, \& Ronning, 1999), moral reasoning (Grayson, 2008), intercultural competence (Arkoudis, Baik, Marginson, \& Cassidy, 2012), and international attitudes (Parsons, 2010). Our study focuses directly on intraclassroom cross-national interactions (CNI) that occur as part of the everyday curricular offerings and serve as formal learning environments where students can interact in diverse educational contexts.

Interactions with diverse perspectives and identities in college classrooms have been shown to be significant factors correlated with student learning and outcomes, intercultural competence development (Bowman, 2010; Deardorff, 2006; Denson \& Chang, 2009; Hurtado, 2001; Lee, Poch, Shaw, \& Williams 2012), and academic engagement (Zhao \& Douglass, 2012). A study in US and Australian universities (Parsons, 2010) indicated that social contact with international students (as one of the components of an internationalized curriculum) significantly predicted higher scores on most scales associated with desired outcomes of curriculum internationalization (i.e., international attitudes and perceptions; cross-cultural skills, and international behaviours). It is not always clear, however, what opportunities for student interaction were offered in the classroom, and what the role of faculty and instructors was in leveraging international diversity.

\section{The Role of Academic Staff in Facilitating CNI}

Facilitating interactions among students from different national backgrounds can be a challenging process for instructors (see Matsuda, Saenkhum, \& Accardi, 2013), as it relates to pedagogic practices. One common concern is that, if such interactions are not facilitated by instructors in the classroom, domestic students may fail to benefit from contact with other cultures and thus fail to benefit from campus diversity, as the mere presence of international students, even in large numbers, is insufficient in itself to promote intercultural interactions with cultural "others" (Andrade \& Evans, 2009; Leask, 2009) and to result in mutually beneficial cross-cultural understanding.

Internationalization scholars have identified a gap in literature that relates directly to classroom interactions of international and host country national students. Leask and Carroll (2011) noted that institutional agents often assumed there would be automatic cultural benefits as a result of increased international student enrolment, but noted that there was rarely an institutional process for facilitating outcomes. Instead, research has tended to focus on concerns by instructors about how to respond to culturally and linguistically diverse students (Matsuda et al., 2013), often viewing students' needs from the deficit perspective. Such research has not addressed how the facilitation of cross-national interaction in classrooms may accomplish institutional or instructional goals (Green, 2012; Jones \& Killick, 2013; Leki, 2006; Zamel \& Spack, 2004), nor the conditions under which such outcomes may be attainable.

The need to facilitate intercultural interactions to achieve expected outcomes international diversity can bring to the classroom was predicted by Allport (1954), whose contact hypothesis suggests that the individuals need to have common purpose or shared work, and equal status for 
meaningful infraction to occur across cultural lines. Such interactions require deeper engagement with the cultural "other" and his/her perspectives (Cruickshank, Chen, \& Warren, 2012) as well as how alternative perspectives and peers' cultural backgrounds relate to concrete tasks and goals in shared work (Pettigrew \& Tropp, 2006). As applied to the learning environment in college classrooms, there has also been increasing focus in the literature on understanding how faculty members and instructors may engage international diversity in the classroom to enhance cultural learning for all students in the classroom (Leask, 2009; Zhao \& Douglass, 2012). Several authors also note the need for instructor facilitation to ensure and support in-class cross-cultural interactions because undergraduate students tend to work with other students from a similar culture and linguistic background, experience anxiety during such interactions (Dunne, 2009), and rarely seek out diverse interactions without being prompted by the instructor (Arkoudis et al., 2010).

\section{Rationale for Study}

The rationale for our study is twofold. First, as internationalization and, specifically, the components of IaH, continue to be a common practice in U.S. higher education institutions, data points at various levels of institutional activity (e.g., administration, teaching and learning, student life) will help to inform the broader agenda of IaH. In this study, we focus our efforts specifically on international student interactions within postsecondary classrooms. Additionally, our study seeks to better understand the outcomes of cross-national interactions in postsecondary classrooms as experienced by students from the United States, international students within U.S. postsecondary classrooms and the academic staff who are simultaneously responsible for facilitating classroom activities (Tange \& Jensen, 2012).

Our questions are framed in the broad conceptual framework of internationalization of higher education and the role that international students play (or do not play) in this process. Understanding this process further will depend on answering our two research questions:

1. What are the perceived outcomes experienced by domestic and international students who participate in cross-national interactions in postsecondary classrooms?

2. What do students and faculty perceive to be the most effective ways that instructors facilitate cross-national interactions?

\section{Methods}

\section{Participants}

Data reported in this study draws upon a larger dataset based on the multi-year study on contributions of international students to campus internationalization that was conducted on three campuses of a public university system in the Midwest region of the United States. Our sample featured self-selected students and invited instructors from an urban research-intensive campus, a rural liberal arts-focused campus, and a rural comprehensive undergraduate campus within this university system. Our aim was to better understand a wide variety of classroom settings, so we also selected both students from multiple academic fields. 
In total, we engaged 121 students, both international (IS) and domestic (DS). For the purposes of our research, we defined international students as those who are holding a student visa. Although we continue to be very interested in outcomes and experiences of students who are immigrants to the U.S., our focus on this study was on international students who have finite student visas because they are frequently a formal component of campus internationalization plans. Table 1 provides an overview of the interview sample. Our sample reflects an effort to over-sample international students: this population comprises approximately $10 \%$ of the total institutional population, but approximately $30 \%$ of the students interviewed were international students. Our over-sampling was aimed at understanding a wide variety of international student perspectives. The students were self-selected as we invited volunteers to participate in the study.

In addition to students, we sought to better understand teaching-learning dimensions from those who were leading the process. We solicited volunteers from a purposive sample of instructors based on their interest in and support of campus internationalization initiatives and/or existing contacts within the departments. In total, we included 47 teaching faculty on three campuses. On the flagship campus of the university we interviewed 26 faculty members from three disciplines, while interviewing six faculty members from the university's liberal arts undergraduate campus, and a third from the comprehensive undergraduate-focused institution in the university system.

\section{Table 1}

Study Participants

\begin{tabular}{lccc}
\hline & Undergraduate Students & Graduate Students & Faculty \\
\hline \hline International (visa) & 30 & 20 & \\
Domestic (citizen or resident) & 50 & 21 & \\
Faculty & & & 47 \\
Total & $\mathbf{8 0}$ & $\mathbf{4 1}$ & $\mathbf{4 7}$ \\
\hline
\end{tabular}

\section{Procedures}

In order to engage as many students as possible, and to examine common themes among students, we interviewed students in focus groups to gain in-depth insights on concepts we were examining and allow participants to build upon or refute each other's response in small groups (Krueger \& Casey, 2000). To this end, we grouped our participants into focus groups in the following four categories: (a) international undergraduate students; (b) domestic undergraduate students; (c) international graduate students; and (d) domestic graduate students. Each focus group interview size ranged from two to eight participants; interviews lasted between 60-90 minutes and were audio recorded. Interview questions centered on student and experiences with CNI. The research team had no direct contact with participating students in classroom context.

Our faculty interviews were of mixed format (i.e., face-to-face and via teleconference and telephone) and largely depended on the availability of faculty. Wherever possible, we conducted 
focus groups using the same procedures as utilized in student interviews. In total we conducted nine focus groups (31 participants) and 16 individual interviews.

\section{Analysis}

Overall, data analysis was divided into three stages. First, we individually read through participant responses relevant to our research questions. In phase two, we analyzed student and faculty responses by independently coding transcripts using NVivo and writing memos on what types of CNI opportunities students described and what were the perceived outcomes of these interactions. During the third stage, data analysts discussed codes, checking for inter-coder agreement (Glaser \& Strauss, 1967). Finally, the analysis team compiled the initial and the emergent codes to reach the consensus on each one, then assigned them to particular sentences or paragraphs that corresponded with codes (Miles \& Huberman, 1994).

\section{Findings}

Two main findings emerged from this study. Our first main finding was one that was unexpected, does not yet seem to have a strong foundation in literature, and was somewhat contradictory within the study itself. Domestic students self-reported that their learning about academic content improved as a result of interactions with international students. Although CNI is often framed as an opportunity for students to improve their intercultural skill as a result of course-based dialogue (Bowman 2010; Denson \& Chang, 2009; Soria \& Troisi, 2013), a theme emerged among domestic students in the study regarding content learning. Both undergraduate and graduate domestic student participants reported having developed multiple perspectives on course content and indicated that international student presence enriched in-class learning and academic engagement when opportunities to share knowledge and perspectives across cultures were provided. One student noted:

In my group project we had German and South Korean students in the group, and hearing and understanding from their perspective how the same kind of psych topics were discussed in their countries and how research over there is handled... that I wouldn't have otherwise learned from the class...So learning more about that is, I think a great opportunity. (Domestic Undergraduate Student A)

At the graduate level, where our sample consisted of students in professional schools, student responses also indicated that they considered CNI an important tool in preparing for future careers by virtue of learning more about different national contexts.

Just getting an insider perspective on everything that's happening in China [is important]. Because, obviously, I can read about it in The Economist or whatever, but it's not like actually hearing from a real-life anecdote of how you actually get business done and make transactions happen. (Domestic Graduate Student A) 
We have students from Korea, from China, Taiwan, Japan, and Austria, Spain, Europe, so it's quite diverse and in the past...I was able to closely collaborate with them in projects, either in class or outside of class as research assistants...we ask questions about their different cultural experiences and perspectives. Like, we exchange [perspectives]. (International Graduate Student D)

Domestic students arguably had an internationalized experience as a result of small group work with international students. This theme, however, was not present in international student perspectives. It is unknown why international students did not feel they received an academic bump from domestic students, but there are likely three explanations. First, learning perspectives from U.S. students may not be novel or surprising to international students. Rather, these students are immersed in U.S. academic culture and may have grown accustomed to U.S. students sharing perspectives. It is also possible that international students do not value CNI as a learning strategy as much as domestic students. Although not all students in this study were educated in Confucian traditions and learning styles, demographics within the university campuses where the research took place indicate that the vast majority of students on U.S. campuses are either from China or South Korea. The Confucian effect is unknown. Some students expressed trepidation with working in groups and spoke of insecurity in their own language, which may have influenced perspectives on CNI.

For international and domestic students alike, cultural understanding was also a perceived benefit of CNI. How the students understood and perceived the cultural outcomes of CNI, however, differed between domestic and international students. Domestic students' responses aligned with the theoretical propositions of cultural intelligence theory as those US students who reported benefits from CNI appeared to be developing the drive for cultural intelligence outlined by Ang, Van Dyne, and Koh (2006). For U.S. students, positive perceptions of CNI occurred when the domestic students initiated the desire to learn more. Students perceived benefits when they were willing to move into more in-depth conversations about each their group mates' culture. For example, some students noted the benefits of addressing the underlying process of reflecting on their own culture and examining their own preconceived cultural notions and stereotypes of cultural difference.

One main thing that I learned is that a lot of people think that if someone doesn't have that great of English, they're not intelligent, which is not the case at all. And I think that's a lot of times why people get pushed to the side, because they struggle with English. But really, it's probably their second language, or third, or fourth ... Just because they struggle with English doesn't mean their insight isn't valuable. (Domestic Undergraduate Student B)

Certainly, you find a lot of similarities between each other, but you also find that the differences that we share are useful, especially to work together and use those differences, different skills, different abilities, different mindsets. And that helps a collaborative effort work. (Domestic Undergraduate Student C) 
The drive to engage interculturally, however, manifested itself differently in international students. In this case, international students spoke of opportunity to gain emic perspectives about life in the U.S. For one student, this provided an opportunity to challenge her existing beliefs and value systems about Americans' cultures, opinions, approaches to academic work and what is "really going on in America" (International Undergraduate Student). In this example, students were seeking out conversations as a way of understanding the culture beyond what was represented to them in media, classroom content, and university messaging. During this process, international students appeared to be enlisting U.S. students as cultural interpreters (Katan, 2014), as one student shared:

There are some cultural issues behind [grammar] — like it's grammatically correct, but when Americans hear it, it's just not... appropriate. Or they will take it in a different way than what you intended to. So there's some cultural ways of thinking, or you need knowledge behind it, too. And I have American peers who sometimes help me confirm [ideas], or double check, you know, sometimes I let them go through it, if it's important for me or they have time and they are willing to help me with that. (International Graduate Student D)

What is likely the most relevant, and likely the most intuitive finding in this section, is that students experience group work benefits differently. For U.S. students, who may have less experience in the countries of origin of their international classmates, these classmates represent an opportunity to view content within new contexts. Domestic students also expressed a sense of discovery and new culture learning that occurred in these groups. International students on the other hand, are already immersed in the U.S. environment. They are surrounded by academic content, teaching styles, and peers from the U.S. who are more often than not the majority in classes. For international students, culture learning manifested itself in more strategic thinking. U.S. students were seen as a resource to help understand the intricacies of U.S. culture. The implications of these findings are expanded upon in the Discussion section below.

\section{Discussion}

Our study aimed to better understand the inner workings of cross-national interaction (CNI) in postsecondary education classrooms in the U.S. We located this study in the broader internationalization of higher education literature. In this literature, there appears to be both great hope in the role that international students can play in supporting diversity and internationalization on campus (Zhao et al., 2005) and recognition that faculty often feel unprepared to manage such diversity in their classroom (Matsuda et al., 2013). Our study set out to identify the potential contributions of international students on US campuses by investigating a micro-level space of engagement - classroom group work.

Our pursuit was somewhat open-ended. Our literature review indicated that we might encounter reports of intercultural competence development (Arkoudis et al., 2012) or students 
reporting more internationalized attitudes as a result of cross-national contact (Parsons, 2010). What we found was that results of CNI were nuanced, differed by student population group, and were highly dependent on faculty facilitation. We also learned that not all students enjoy CNI (a topic for further exploration in another study).

\section{Course Content Learning, Resource-Seeking and CNI}

Although themes were at times inconsistent, our first major finding was that domestic students (those who were studying in their own country, in their first language, and in many cases their home community) viewed international students as global content guides. In this case, domestic students were appreciative of the perspectives of international students about the content at hand. Through conversations in groups, domestic students felt they benefited from the unique and new perspectives that international students could share about the course content. We should note that domestic student comments about issues like friendship, global understanding, enhanced worldviews, etc. were rare. Rather, domestic students saw international students as a resource from which to gain new knowledge.

Similarly, international students saw domestic students as resources. International students were studying in an environment that was far from home, potentially in unfamiliar pedagogical environments, and were managing day to day life in a system that was potentially new to them. Further, international students were largely outnumbered by domestic students in discussion groups. Despite all the navigational capital that international students had gained through their time on campus, they claimed they were missing the true story of the United States. This true story was likely a story not presented in official university documents, media, and other outlets. Within groups, international students saw domestic students as cultural interpreters who could provide them with the everyday experience perspective of the United States. Figure 1 (below) is a graphic representation of our findings.

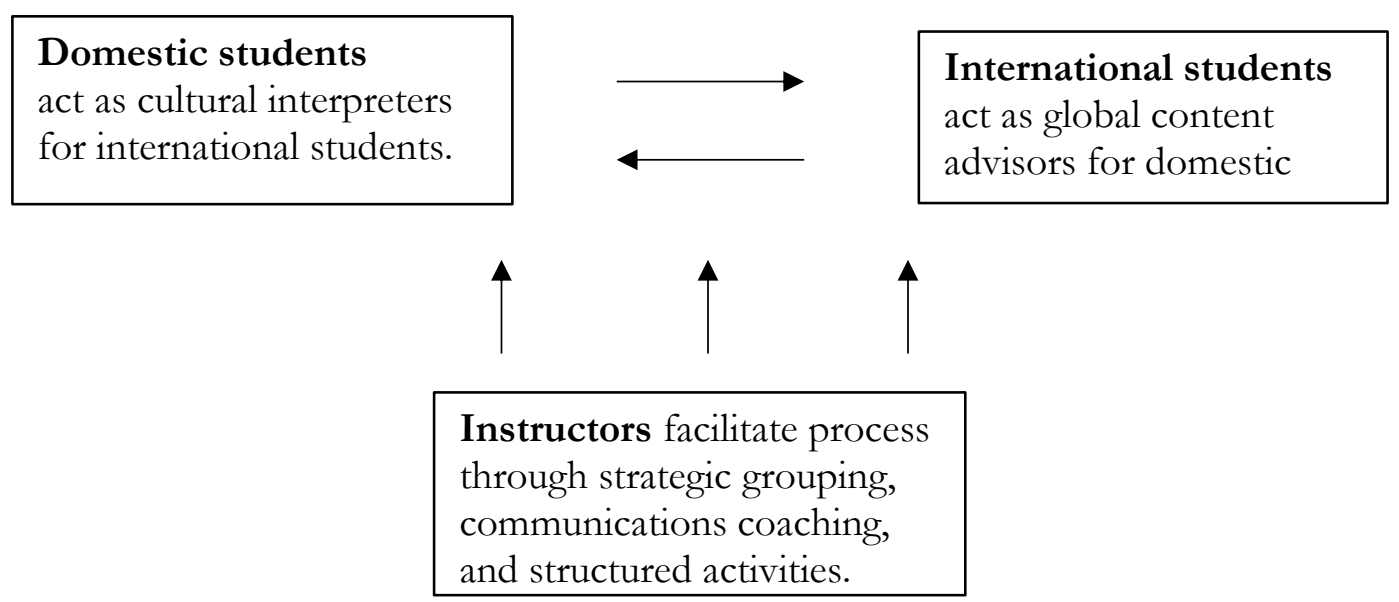

Figure 1. Outcomes of CNI. 


\section{The Role of Academic Staff in Promoting CNI}

As noted above, both international and domestic students in the study reported some benefit from CNI (although students valued different aspects and arguably received differential benefits). Because of this, we sought to understand what the role of instructors was in supporting CNI that was valuable to students. Students at both the undergraduate and graduate levels noted that external structure on group activities is important for supporting CNI. For domestic students, there was a desire to have equal voice in conversations, but a recognition that some students were more verbal than others.

One thing is that in group work...is that...[international student] just sort of feel overwhelmed by the native English speakers who are just... bombarding the group with their verbiage. So that's certainly one challenge, how to make sure that people... are getting their opinions heard, their insights acknowledged. (Domestic Graduate Student B)

[We need to] increase social interaction... because I can't tell you how many times, like, I just feel like we kind of shut each other out, and it's not ... on purpose... I think we do have a lot in common socially, but for whatever reason, we don't give ourselves the opportunity to interact enough, and I think that's where things fall apart when we're in the classroom. (Domestic Undergraduate Student D)

International students echoed the challenges that existed in groups, noting that domestic students minimize the efforts and contributions of international students. One student commented on assumptions about language and the stigmatization that sometimes occurs for students who speak English as a second language.

When you're an international student they just assume that you don't know the language, so there's a patronizing thing that is there that is like, "Oh, it's not your first language, it's not your language." And they don't see the work that has been done because some of them may not be fluent in speaking it, but they would be very good at writing it ... I think it mainly makes you not that happy to be in the class and it's kind of a stressful thing if it's an ongoing thing. (International Graduate Student C)

The assumption or the stereotype that the international students may not be writing as well as their counter American fellows... the first ever project that we had to do together and write a 25 page long single- spaced paper, we were eight people in the group, only two international students... We ended up writing the paper, two of us. So, I guess the stereotype that they thought, "Oh, you know, we're gonna do group work, and meet with them, and you know, it's probably going to be, they can do the research but we should do the writing," It happened the other way around. (International Graduate Student B)

The challenges experienced by both domestic and international students in group settings appeared to be minimized when faculty provided structure or support to group work. Students 
recognized that it was sometimes difficult for them to work through the challenges of group assignments, and that a scaffolded or supported group structure eased challenges in the group.

[Professors] are really aware of the fact that like international students and the language barrier, and they notice that sometimes we usually sit in a bunch of group [sic] with, like, Chinese students together in class with 200 people...they'll sometimes bring that up too and they'll be like, "You know what, it would be better if you can hang out with different people." (International Undergraduate Student E)

Faculty triangulated student findings regarding structuring group activities for maximal interaction, and were able to provide more insights into their instructional intentions than were immediately visible to students. Faculty reported that a first an easy strategy often used was grouping to ensure cross-national communication. Instructors who perceived CNI to be effective in their classrooms drew upon linguistic and cultural diversity in the classroom to enhance cognitive engagement through peer feedback and assessment (Arkoudis et al, 2010). This finding seemed to be especially relevant for graduate students.

I put students in groups quite often ... When I have just a few international students in there, I never make them be the only international student in a group. I always make sure there's at least two. I actually had a speech class once where I only had five Americans and ten international [students], and I made the Americans split up, and they were nervous. And I thought it was good for them to experience that. (Lecturer, Humanities)

In addition to purposeful assignment of students into cross-national teams, those who were most supportive of CNI viewed international students as resources to help all students engage with content knowledge and facilitate deeper learning. Some of their approaches were: utilizing multiple cultural perspectives on content as a teaching and learning resource; shaping projects around countries international students in their classroom came from; and emphasizing the importance of drawing on international student cultural experiences without tokenizing international students.

I've seen students have their assumptions questioned from all different sides. Sort of the assumption that, I don't know, marriage should be based on love. And then you have someone saying, 'Well, not in my country.' And then everyone says, 'Whoa! Different!' And you can see the sort of light bulbs going off, and this is really helpful for [the subject matter learning]. And I think for our field, this is critical. (Faculty Member, Humanities)

Faculty who perceived group work to be an effective element in their classes next modeled behaviors for students after the grouping process. These instructors described setting a communicative tone and purpose for CNI in order to support engagement between students. 
But I do also try to model skills for them to work through group challenges...for instance if there's a group member who's not pulling their weight, or if there's a group member whose communication skills seem to be posing a problem for the others...well, what could you do about that? What kinds of steps could you take either to make it easier for her to communicate with you or vice-versa? And so, really building this sort of group problem solving skill set. (Faculty Member, Technical Communication)

The findings illustrate the importance of an intentionally structured classroom environment with opportunities for interaction, reflection, and instructor support, given that not all student respondents viewed the classroom as a comfortable or appropriate space to engage in purposeful cross-national interactions beyond required group work (some preferred co-curricular environments such as student organizations and clubs). In fact, without structured support and reflection in the classroom, exposure to diversity can lead to reinforcement of negative stereotypes on cultural others (Pettigrew, 2008). However, instructors may wish to leverage the findings of this study to create opportunities for students to discuss specific class content by placing it into international contexts or may specifically ask for reflections on content based on students' everyday experiences.

\section{Conclusion: Making Sense of CNI}

This study provided data that suggests that when domestic and international students enter into group work environments, there is a degree of reciprocal exchange that exists. The reciprocity, however, is not a direct exchange, as domestic and international students both give and receive differently. The finding in and of itself provides nuance and perhaps a new analytic frame for internationalization research. Our literature review discussed outcomes of the presence of international students on US campuses from both institutional and individual frames. Our data suggest, however, that a third unit of analysis may be needed for studies such as ours. We suggest that further research may be conducted at the level of the interaction itself.

The themes that emerged from our study indicate that student engagement in groups creates a degree of exchange between participants. These exchanges can either empowering or thorny. Zhang and Epley (2009) note that within every reciprocal exchange, there is a process of give and take. The authors suggest that challenges emerge when individuals calculate their giving to be more than their receiving and note that this may be inevitable because humans exist in an egotistic frame. Intercultural communication theories (Leask \& Carroll, 2011) and cultural intelligence theories (Earley \& Ang, 2003) suggest that egocentric ethnocentrism can be reduced through the development of cultural skill and competence, which may explain why the students who felt they benefited had appreciation of cultural dimensions (internationalized content and cultural informants). These findings indicate that international students can indeed contribute to campus internationalization and can be assets in group learning environments, but perhaps in ways not yet identified in the literature. Our findings also challenge deficit-oriented perspectives sometimes found in the literature, suggesting that international students are seen as a learning resource by 
their domestic classmates. Likewise, domestic students were seen as a resource by international students.

Finally, our findings also indicated that instructors play a central role in facilitating CNI and helping students overcome associated challenges (e.g., via providing structure or support to group work). However, we are going "beyond the present condition of 'good' lecturers and 'deviant' learners" (Tange \& Jensen, 2012, p. 191), as those instructors supportive of CNI viewed international and domestic students as resources to help each other engage with content knowledge and facilitate deeper learning.

This micro-study of CNI across three campuses provided qualitative evidence of how learning takes place in groups and what instructors might do to support the process. The interaction of the three key actors in CNI (i.e., domestic students, international students, and instructors) indicates that if any one of the parties was missing, the specific outcomes described in this article may disappear. To this end, further investigation of CNI as a strategy for classroom and campusbased internationalization is warranted. At the same time, the findings that emerged from this study indicate that there are limitations to CNI and, like any pedagogical approach, there are benefits and drawbacks to its use. Thoughtful structuring of CNI opportunities, however, may contribute to campus internationalization strategy by providing students with broad perspectives nested in finite, short-lived classroom-based discussion.

\section{References}

Allport, G. W. (1954). The nature of prejudice. Reading, MA: Addison-Wesley.

American Council on Education. (2016). Student mobility. Retrieved from http://www.acenet.edu/highereducation/topics/Pages/Student-Mobility.aspx

Andrade, M. S., \& Evans, N. W. (2009). International students: Strengthening a critical resource. Lanham, MD: Rowman \& Littlefield.

Ang, S., Van Dyne, L., and Koh, C. (2006). Personality correlates of the four-factor model of cultural intelligence. Group Organization Management, 31(1), 100-123.

Arkoudis, S., Yu, X., Baik, C., Chang, S., Lang, I., Watt, K., \& Lang, J. (2010). Finding common ground: Enhancing interaction between domestic and international students. Guide for academics. Melbourne, Australia: Australian Learning and Teaching Council. Retrieved from: http://aiec.idp.com/uploads/pdf/2010 Arkoudis Thu 1600_B104.pdf

Arkoudis, S., Baik, C., Marginson, S., \& Cassidy, E. (2012). Internationalising the student experience in Australian tertiary education: Developing criteria and indicators. Melbourne, Australia: Centre for the Study of Higher Education, University of Melbourne. Retrieved from https://melbournecshe.unimelb.edu.au/ data/assets/pdf file/0010/1490851/Janu 2012 AEI indicators.pdf

Bowman, N. A. (2010). Assessing learning and development among diverse college students. New Directions for Institutional Research, 145, 53-71.

Bruning, R. H., Schraw, G. J., \& Ronning, R. R. (1999). Cognitive psychology and instruction. Upper Saddle River, NJ: Prentice-Hall.

Childress, L. K. (2009). Internationalization plans for higher education institutions. Journal of Studies in International Education, 13(3), 289-309. 
Crowther, P. M., Joris, M., Otten, B., Nilsson, H., Teekens, H., \& Waechter, B. (2000). Internationalisation at home: A position paper. Amsterdam, Netherlands: European Association for International Education. Retrieved from: https://www.internationalisering.nl/wpcontent/uploads/2015/04/Internationalisation-at-Home-A-Position-Paper.pdf

Cruickshank, K., Chen, H., \& Warren, S. (2012). Increasing international and domestic student interaction through group work: A case study from the humanities. Higher Education Research and Development, 31(6), 797-810.

Deardorff, D. (2006). Identification and assessment of intercultural competence as a student outcome of internationalization. Journal of Studies in International Education, 10(3), 241-266.

Denson, N., \& Chang, M. J. (2009). Racial diversity matters: The impact of diversity-related student engagement and institutional context. American Educational Research Journal, 46(2), 322-353.

Dunne, C. (2009). Host students' perspectives of intercultural contact in an Irish university. Journal of Studies in International Education, 13(2), 222-239.

Earley, P. C., \& Ang, S. (2003). Cultural intelligence: Individual interactions across cultures. Palo Alto, CA: Stanford University Press.

Glaser, B. G., \& Strauss, A. L. (1967). The discovery of grounded theory: Strategies for qualitative research. Chicago, IL: Aldine.

Grayson, J. P. (2008). The experiences and outcomes of domestic and international students at four Canadian universities. Higher Education Research \& Development, 27, 215-230.

Green, M. F. (2012). Measuring and assessing internationalization. Washington, D.C.: NAFSA: Association of International Educators. Retrieved from http://www.uky.edu/toolkit/sites/ www.uky.edu.toolkit/files/Measuring\%20and\%20Assessing\%20Internationalization.pdf

Hurtado, S. (2001). Linking diversity and educational purpose: How diversity affects the classroom environment and student development). In G. Orfield (Ed.), Diversity challenged: Evidence of the impact of affirmative action (pp. 187-203. Cambridge, MA: Harvard Education Press.

Jones, E., Coelen, R., Beelen, J., \& de Wit, H. (Eds.). (2016). Global and local internationalization. Rotterdam, Netherlands: Sense.

Jones, E., \& Killick, D. (2013). Graduate attributes and the internationalized curriculum: Embedding a global outlook in disciplinary learning outcomes. Journal of Studies in International Education, $17(2), 165-182$.

Katan, D. (2014). Translating cultures: An introduction for translators, interpreters and mediators. London, UK: Routledge.

Knight, J. (2015). Updating the definition of internationalization. International Higher Education, 33, 2-3.

Krueger, R. A., \& Casey, M. A. (2000). Focus groups: A practical guide for applied research (3rd ed.). Thousand Oaks, CA: SAGE.

Leask, B. (2009). Using formal and informal curricula to improve interactions between home and international students. Journal of Studies in International Education, 13(2), 205-221.

Leask, B., \& Carroll, J. (2011). Moving beyond 'wishing and hoping': Internationalisation and student experiences of inclusion and engagement. Higher Education Research \& Development 30(5), 647659.

Lee, A., Poch, R., Shaw, M. A., \& Williams, R. (2012). Engaging diversity in undergraduate classrooms: A pedagogy for developing intercultural competence. San Francisco, CA: Jossey-Bass.

Leki, I. (2006). Negotiating socioacademic relations: English learners' reception by and reaction to college faculty. Journal of English for Academic Purposes, 5(2), 136-152. 
Matsuda, P. K., Saenkhum, T., \& Accardi, S. (2013). Writing teachers' perceptions of the presence and needs of second language writers: An institutional case study. Journal of Second Language Writing, $22(1), 68-86$.

Miles, M. B. \& Huberman, A. M. (1994) Qualitative data analysis: An expanded sourcebook (2nd ed.). Thousand Oaks, CA: SAGE.

Parsons, R. (2010). The effects of an internationalized university experience on domestic students in the United States and Australia. Journal of Studies in International Education, 14(4), 313-334.

Pettigrew, T. F. (2008). Future directions for intergroup contact theory and research. International Journal of Intercultural Relations, 32(3), 187-199

Pettigrew, T. F., \& Tropp, L.R. (2006). A meta-analytic test of intergroup contact theory. Journal of Personality and Social Psychology, 90(5), 751-783.

Shapiro, S., Farrelly, R., \& Tomaš, Z. (2014). Fostering international student success in higher education. Alexandria, VA: TESOL.

Soria, K. M., \& Troisi, J. (2013). Internationalization at home alternatives to study abroad: Implications for students' development of global, international, and intercultural competencies. Journal of Studies in International Education, 18(3), 261-280.

Tange, H., \& Jensen, I. (2012). Good teachers and deviant learners? The meeting of practices in university level international education. Journal of Research in International Education, 11(2), 181193.

Zamel, V., \& Spack, R. (2004). Crossing the curriculum: Multilingual learners in college classrooms. Mahwah, NJ: Lawrence Erlbaum.

Zhang, Y., \& Epley, N. (2009). Self-centered social exchange: Differential use of costs versus benefits in prosocial reciprocity. Journal of Personality and Social Psychology, 97(5), 796-810.

Zhao, C. M., \& Douglass, J. A. (2012). Critical mass and the international student effect: A profile at a group of major US universities. Berkeley, CA: Center for Studies in Higher Education.

Zhao, C. M., Kuh, G. D., \& Carini, R. M. (2005). A comparison of international student and American student engagement in effective educational practices. Journal of Higher Education, 76(2), 209-231.

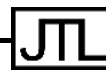

